\title{
Economia e educação: a contribuição de Álvaro Vieira Pinto para o estudo histórico da tecnologia
}

\author{
Marcos Cezar de Freitas
}

Pontifícia Universidade Católica de São Paulo,

Programa de Estudos Pós-Graduados em Educação: História, Política, Sociedade

\section{Introdução}

Este artigo analisará a lenta construção do conceito de "trabalho tecnologicamente elaborado", desenvolvido no transcorrer de três décadas por Álvaro Vieira Pinto, intelectual de grande prestígio no início da década de 1960.

Vieira Pinto atuou principalmente no Rio de Janeiro, na antiga Faculdade Nacional de Filosofia (FNFi) e no Instituto Superior de Estudos Brasileiros (ISEB), fundado em 1956 e fechado em 1964, após o golpe militar. Foi também pesquisador visitante do Centro Latinoamericano de Demografia, do Chile.

O texto abordará, principalmente, o longo percurso investigativo do autor, que examinou exaustivamente o conceito de "amanualidade" originado nas filosofias existencialistas européias e o submeteu àquilo que denominava "realidade nacional". $\mathrm{O}$ conceito de amanualidade permitiu ao autor de Ideologia e desenvolvimento nacional (1956) pensar continuamente nos temas técnica, tecnologia e educação.

O objetivo deste trabalho consiste em elucidar suas expectativas em relação ao jovem considerado "arcaico". Esse arcaísmo resultava, no seu entender, do manuseio de técnicas pouco elaboradas, ou seja, resultava de uma realidade subdesenvolvida que negava à juventude a apropriação, em proveito próprio, de tecnologias mais sofisticadas.

Sua forma de entender e valorizar o contínuo envolvimento com a tecnologia no quotidiano das pessoas "rústicas", e o caráter socialmente emancipador que atribuía à distribuição social das técnicas mais sofisticadas, despontaram em sua obra após um longo percurso de leitura e produção solitária de tratados filosóficos.

Desde a publicação de Consciência e realidade nacional (1960) até a publicação recentíssima de $O$ conceito de tecnologia (2005), passando por Ciência e existência (1979) e por El pensamiento crítico en demografía (1979), sua obra abrigou uma densa reflexão sobre o significado social da filosofia em lugares pobres. Essa densa reflexão, contudo, enfrentou e enfrenta grandes obstáculos para chegar ao conhecimento de um público mais amplo. Um exemplo disso é que somente agora seu magnífico estudo O conceito de tecnologia foi editado. Isso significa 
que gerações discutiram o tema desenvolvimento sem conhecer um dos mais completos tratados sobre o tema e, principalmente, sem considerar a dimensão política que autor atribui à disseminação do trabalho tecnicamente elaborado em sociedades pobres, como a nossa.

$\mathrm{O}$ autor, perplexo diante das possibilidades que enxergava para a juventude brasileira, procurou em Hegel e depois em Marx argumentos com os quais pudesse recusar a crença de que a tecnologia "necessariamente" se vincula à opressão social.

Considerando o trabalho tecnologicamente elaborado um direito e uma prerrogativa da juventude brasileira, indicava a importância de desmistificar a rusticidade em defesa daquilo que chamava de "interesse nacional". Para desmistificar as muitas falas que na década de 1960 produziam uma espécie de elogio da rusticidade, criticou energicamente a filosofia heideggeriana.

É desse percurso analítico que este artigo trata, tendo por pano de fundo o contexto que possibilitou a reelaboração dos conceitos de desenvolvimento e subdesenvolvimento no Brasil e na América Latina.

\section{As origens de um argumento}

A obra quase clandestina de Vieira Pinto obedeceu a uma lógica de construção argumentativa contínua e complementar, a qual, vista no seu conjunto, revela o paciente esforço dedicado à construção solitária de um portentoso projeto: enunciar as implicações antropológicas e antropomórficas do conceito "trabalho".

Seus livros foram publicados com intervalos não menores que uma década, e cada um apareceu como se fosse mais uma peça de quebra-cabeça, que, uma vez encaixada, revelava os traços de seu desenho interpretativo: um mundo visto de baixo para cima, com especial destaque àquilo que os homens conseguem fazer com os instrumentos que têm ao alcance das mãos.

Alguns se lembram de seu nome associando-o à formação filosófica do educador Paulo Freire, que publicamente o chamava de "mestre". Outros tantos chegaram indiretamente aos seus escritos com a mediação da produção acadêmica que se apresentou a partir da década de 1980 (Franco, 1985; Rodrigo, 1988; Paiva, 1986; Toledo, 1982, 1986).

Predomina no conjunto de dissertações, teses e livros que abordaram sua obra a opinião, apresentada com maior ou menor benevolência, conforme o caso, de que Vieira Pinto deveria ser compreendido como expressão do "seu contexto". Sobre o autor paira a sombra de uma situação histórica cujas marcas no panorama intelectual do Brasil do século XX, na opinião de muitos, indicam que a sintonia entre o "homem de pensamento" e o momento em que desfrutou de maior visibilidade se deu porque o professor de história da filosofia, mesmo com um temperamento reconhecidamente reservado, foi capaz de protagonizar o papel de "ideólogo do desenvolvimento".

De forma sintética, pode-se dizer, então, que estamos diante de um intelectual lembrado pelo contexto do "desenvolvimentismo" do após Segunda Guerra, e que, segundo a maior parte dos seus analistas, seus escritos foram produzidos como panfletos destinados à defesa do desenvolvimento econômico para a consolidação de um projeto nacional. De forma ao mesmo tempo inversa e complementar a esse tipo de opinião, alguns acrescentam que, na realidade, o autor defendia um projeto nacional como única alternativa viável para alcançar o assim chamado desenvolvimento econômico (cf. Roux, 1990).

Na maioria dos estudos que se ocuparam com a trama da qual Vieira Pinto foi personagem, o ponto de partida do intelectual acaba assumindo a condição de ponto de chegada, ou seja, o autor é lembrado porque teve a oportunidade de se expor nas atividades do Instituto Superior de Estudos Brasileiros (ISEB), fundado em 1955 e aberto ao público em 1956, na cidade do Rio de Janeiro. Lá pôde publicar um estudo com

${ }^{1}$ A expressão "homem de pensamento" não é casual. O editor Ênio Silveira, seu admirador confesso, dizia que Vieira Pinto era a antítese perfeita do "homem de ação". 
mais de mil páginas intitulado Consciência e realidade nacional.

Basta percorrer os escritos da maioria dos seus analistas, os que "aplaudiram e os que vaiaram", para perceber que o autor é lembrado como integrante de um instituto e como autor de um livro que supostamente expressaria o "espírito de um tempo", para usar uma expressão de Karl Mannheim, autor prestigiado no circuito isebiano.

Como será exposto a seguir, tanto o ISEB como o livro Consciência e realidade nacional exibem apenas um trecho do seu périplo ao redor do continente que decidiu circunavegar: o conceito trabalho. O ISEB desgrudou-o de sua circulação inicial entre os intelectuais católicos, como o circuito Alceu Amoroso Lima, por exemplo. Este avalizou sua contratação na Faculdade Nacional de Filosofia, onde se tornou catedrático em 1951 defendendo uma tese sobre a cosmogonia de Platão, escrita na França.

O ISEB aproximou-o de sociabilidades mais abertas à mobilização política, como os estudantes, por exemplo, e também das atividades voltadas ao diálogo com os segmentos populares. A Editora Civilização Brasileira confiou a ele a direção do projeto "Cadernos do povo brasileiro". ${ }^{2}$ Já o livro Consciência e realidade nacional the proporcionou a oportunidade de lançar, em 1960, as bases de sua hermenêutica, essenciais para o entendimento de seus futuros escritos e, por isso mesmo, insuficientes para o efeito de síntese de sua tumultuada trajetória.

É bastante provável que seus principais escritos tenham sido elaborados entre 1955 e 1975, período no qual dedicou sua sistemática e disciplinada capacidade de escrever à tarefa de entrelaçar conceitos, expostos em trabalhos distintos, com os quais se manteve fiel a um propósito investigativo: compreender o lugar do trabalho e da forma de trabalhar na confi-

${ }^{2}$ Vieira Pinto escreveu o Caderno de n. 4, intitulado Por que os ricos não fazem greve?, que lhe rendeu alguma popularidade no meio estudantil. guração cultural do povo brasileiro e no horizonte político da sua juventude.

A teia analítica que teceu ao redor do conceito trabalho, no transcorrer de duas décadas, custa a aparecer porque os escritos estão/estavam dispersos e somente agora se pode colocar sobre a mesma mesa as quatro pontas do quadrilátero que oferecem a situação de conjunto com a qual se pode esquadrinhar sua plataforma conceptual: Consciência e realidade nacional, El pensamiento crítico en demografía, Ciência e existência e, mais recentemente, $O$ conceito de tecnologia.

O conceito de tecnologia, por exemplo, originouse de um manuscrito de quase 1.500 páginas que talvez não tivesse sido escrito sem a produção prévia das 1.070 páginas de Consciência e realidade nacional.

Para compreender a relação entre o primeiro e o quarto livros no seu círculo conceitual, é preciso prestar atenção ao momento inicial da circulação do "idioma cepalino" produzido pela Comissão Econômica para América Latina (CEPAL), na década de 1950, no Chile.

É necessário perceber a apropriação dos pressupostos da CEPAL na origem dos escritos mais densos de Vieira Pinto. Reconhecida a apropriação singular do léxico cepalino formulado a partir dos escritos de Raul Prebisch (1950, 1951), o que ocorria em vários ambientes intelectuais, muito especialmente no ISEB, ver-se-á que Vieira Pinto encontrou, naquela economia política que nascia, um "lugar argumentativo" para desaguar seu incomensurável acervo de leituras filosóficas e sociológicas.

Não é correto simplesmente atribuir a Vieira Pinto a condição de filiado teórico aos escritos de Prebisch e nem mesmo de Celso Furtado, o qual, em seus depoimentos autobiográficos, disparou críticas contundentes àquilo que chamava de "nacionalismo exacerbado de Vieira” (Furtado, 1985). Todavia, é necessário observar que algumas novidades teóricas cepalinas introduziam um estruturalismo analítico (Bielschowsky, 1995) que sugeria uma dinâmica interpretativa complementar entre a análise do subdesenvolvimento econômico e os repertórios da filosofia familiares a Vieira Pinto. 
Se a teoria cepalina se projeta a partir dos conceitos "centro e periferia", a plataforma conceptual de Vieira Pinto projetou-se com as respostas que ofereceu para a seguinte questão: o que é trabalhar na periferia sob a dominação econômica e cultural do centro?

Tanto nos escritos cepalinos quanto nos escritos de Vieira Pinto, a dicotomia centro/periferia oferece condições para uma compreensão singular do impacto da propagação do incremento tecnológico e da utilização da técnica para a substituição do trabalho manual. O que se verá adiante é que, na acepção de Vieira Pinto, o centro capturava para si um dos significados da tecnologia e ideologicamente o proclamava como universal, reservando ao mundo da periferia a condição de "paciente receptor" das inovações técnicas, quando, na verdade, já se pronunciava uma "fase histórica" na qual já era possível atuar como "agente propulsor" do próprio desenvolvimento, sem aguardar as demandas do capital externo.

Em ambos os escritos, os cepalinos e os de Vieira Pinto, as noções de centro e periferia eram usadas para descrever uma situação assimétrica na apropriação de ganhos originados na "divisão internacional do trabalho".

Essa divisão internacional do trabalho não se sustentava mais como hipótese descritiva e conceitual à medida que, com a recusa dos cânones da economia clássica, a análise cepalina identificava um processo de severo distanciamento entre ricos e pobres, ficando o centro num plano de desenvolvimento inalcançável pela periferia. Isso se dava à medida que se percebia que, quanto mais o centro se apropriava dos benefícios da produção industrializada, mais a periferia chafurdava no contínuo empobrecimento a que estava condenada.

Na interpretação de Prebisch (1950), o processo de empobrecimento derivava de uma "deterioração nos termos de troca" em virtude da qual a periferia tudo transferia para o centro, inclusive seus parcos ganhos, sem que se realizasse o princípio defendido por David Ricardo de que o desnível entre as partes teria um ponto de compensação assegurado pela transferência de benefícios e ganhos através dos jogos de mercado. Nesse jogo desigual, deteriorado, a periferia tudo entregava e o centro tudo recebia.

O mesmo argumento é defendido por Vieira Pinto, que, em companhia de Roland Corbisier, advogava a tese de que a periferia "exportava o seu ser e importava o não-ser", alimentando, em termos prebischianos (1951), a convicção de que naqueles moldes a divisão internacional do trabalho era uma fonte de disparidades incontornáveis.

Vieira Pinto compartilhava da tese de que, no centro, o crescimento industrial havia tocado amplos setores da sociedade, acrescentando, de uma forma mais homogênea, produtividade e qualidade de vida às populações envolvidas com o mundo do trabalho assalariado, renovando especialmente a participação da juventude nos processos contínuos de desenvolvimento econômico.

Já na periferia, apenas os setores envolvidos com a industrialização do centro, especialmente exportadores de matéria-prima, beneficiaram-se de forma concentrada dos avanços tecnológicos. Com isso se produziu, em decorrência, um distanciamento abissal em relação às outras esferas de trabalho assalariado e nãoassalariado da periferia. Vieira Pinto encontrará nesses setores privilegiados algo que denominará "consciência ingênua", que será retomada mais à frente.

No âmbito da circulação do idioma cepalino, Vieira Pinto interveio com o propósito de explicitar os efeitos da passagem do subdesenvolvimento para o desenvolvimento no mundo do trabalho. Empreendeu essa intervenção com o conceito de "amanualidade".

\section{Da idéia de trabalho elaborado}

Segundo Vieira Pinto, o homem "necessariamente" trabalha, e quanto mais elaborada é a sua capacidade de trabalhar, mais humanizado ele se torna. $\mathrm{O}$ fruto de seu trabalho é a fonte básica para o estudo antropológico de sua existência, uma vez que na relação entre homem e utensílio se apresenta o "grau de domínio" que o sujeito tem sobre o objeto, ou, inversamente, o "grau de subordinação" que a situação lhe 
impõe. ${ }^{3}$ Há algo da forma-homem na forma-trabalho e vice-versa. Por isso o conceito trabalho é uma chave de leitura "antropomórfica" da sociedade:

Uma coisa é mexer-se um pouco de barro, outra é segurar uma vasilha para beber, e outra ainda é tomá-la nas mãos para apreciar a beleza dos desenhos e do colorido que lhe foi dado pela arte cerâmica. Nos três casos imaginados como exemplo temos a mesma matéria, mas três graus diferentes de manuseio, representados por três modalidades de ser, com tudo quanto há de significado particular para cada um; e o que determina a diferenciação entre estes três modos é a operação do trabalhador, que imprime em cada caso à substância bruta original propriedades que condicionam as diferentes possibilidades de manuseio. Com efeito, é o trabalho que eleva a realidade a um outro grau de amanualidade. E com essa elevação surgem concomitantemente novas características do objeto. (Vieira Pinto, 1960,

p. 69, v. 1)

Passar do subdesenvolvimento para o desenvolvimento, na acepção de Vieira Pinto, significava trocar a relação de "amanualidade" entre o homem e o mundo, ou seja, proporcionar a cada um a possibilidade de manusear a realidade com recursos cada vez mais elaborados.

Considerava o homem do povo, o trabalhador manual, seus filhos e filhas, portadores de uma percepção da realidade diferenciada, mas não "menor" em qualidade quando comparada à visão de mundo ostentada pelas classes dominantes.

A consciência crítica, assim como a apresenta Vieira Pinto, é sempre um patrimônio das massas. Enquanto atributo dos trabalhadores, essa consciência torna-se crítica quando o homem passa a ter clareza

${ }^{3}$ Esse tipo de raciocínio foi utilizado por alguns de seus comentadores para demonstrar o quanto Vieira Pinto trouxe para os seus escritos perspectivas analíticas originadas nas filosofias existencialistas. A recriação de uma espécie de "fenomenologia da situação" contribuiu também para que ele fosse considerado "matriz" da obra de Paulo Freire (Paiva, 1986). de que "deve" mudar a realidade. A noção de "dever fazer", adquirível num processo educativo, consolida-se num movimento em que o jovem consegue reunir dedução com indução, ou seja, quem precisa mudar o mundo descobre "o porquê" no mesmo momento em que descobre o "como" transformar a realidade, que passa, então, a ser percebida como mutável.

Se a consciência crítica se faz quando o trabalhador se apropria de um "dever fazer" ao mesmo tempo em que explica por que e como realizar seu intento, o que torna crítica essa consciência apropriada é justamente a ação daqueles que precisam efetivamente mudar o mundo.

Quem não precisa mudá-lo, porque da imutabilidade se beneficia, ou porque, mesmo percebendo a premência da mudança, opta pelos mecanismos tradicionais de progresso e estabilidade, reveste-se da consciência ingênua que contém o ponto de vista de quem não fez da reflexão uma passagem "da consciência em si para a consciência para si”.

Essa maneira de enunciar a presença de uma consciência que já se tem, mas da qual ainda é necessário "tomar posse", fez dos primeiros escritos de Vieira Pinto um conjunto argumentativo com o qual o autor demonstrava sua passagem do continente kantiano para o continente hegeliano, onde se instalou por muito tempo.

Para expor sua compreensão dos conceitos de trabalho e de tecnologia, indicou a forma pela qual o conceito de amanualidade deveria ser (re)utilizado no Brasil, retirando-o dos condomínios analíticos do existencialismo francês (Vieira Pinto, 1960, p. 68, v. 1).

Vieira Pinto reconhecia como válida a hipótese de que o mundo se apresenta ao existente humano como campo das ações possíveis. Estas revelam-se mediante a ação específica sobre os objetos dispostos ao redor do homem, os quais podem ser tomados como utensílios (idem, ibidem).

Diante disso, o autor empreende uma operação conceitual muito assemelhada ao método lukacsiano, o que lhe permite afirmar que estudar o trabalho e a tecnologia corresponde a investigar a cultura daqueles que têm acesso imediato à realidade, como diria Lukács. 
Sua valorização do trabalho industrial decorria da convicção que tinha de que o homem, ao executar tarefas mais elaboradas, especialmente aquelas que são feitas com a mediação da máquina, passa a expressar sua consciência (já existente) de forma progressivamente mais clara. Seu diagnóstico sempre foi contundente: o trabalho exercido sobre o mundo que está à mão é aquele que o transforma eficazmente (Freitas, 1998, p. 93).

Em razão disso, num momento no qual apenas começava a ler Marx, julgava ser conveniente "adaptar" algumas conclusões originadas na economia política marxiana, para que somassem com alguns pressupostos que assimilava do léxico cepalino, e, com isso, compunha o que considerava ser uma receita adequada às particularidades do "terceiro mundo". ${ }^{4}$

Considerava necessidade premente, para a substituição de uma etapa inferior por outra superior de desenvolvimento, fazer com que esse processo fosse precedido e acompanhado de uma intensa "acumulação de trabalho". Tal noção de acumulação, como que numa volta redonda, derivava de sua concepção de técnica, considerada por ele "acumulação qualitativa de trabalho". Qualidade, nesse sentido, queria dizer: "fazer o novo como desdobramento do antigo, logo, desenvolver" (Vieira Pinto, 1960, p. 79, v. 1).

Só há saber novo com avanço técnico. Se uma parte da humanidade já demonstrava usufruir benefícios da apropriação social da tecnologia, restava ao intelectual engajado explicar as causas dos "entraves históricos" ao desenvolvimento nacional em países como o Brasil, rico e pobre ao mesmo tempo. Aliás, se existe um traço peculiar que pode ser atribuído à "geração isebiana", com todo exagero que essa expressão

${ }^{4}$ Conceito este que foi decisivo para que Vieira Pinto, na fase do exílio, ampliasse as bases de sua reflexão, evadindo-se do nacionalismo dos primeiros escritos para adentrar no território político do "internacionalismo terceiro-mundista", cujas referências para ele, no final da década de 1960, provinham de lugares e de nomes diferentes como Tito, Franz Fanon, Gamal Nasser ou Bandung, Nova Délhi e Pequim, por exemplo. contém, esse traço pode ser reconhecido na atenção contínua às concomitâncias da sociedade. Trata-se de outra herança da CEPAL: perceber que o subdesenvolvimento não é uma situação assemelhada ao passado do mundo desenvolvido. É, ao contrário, concomitante a ele e, na maioria dos casos, resultante da deterioração nos termos de troca entre as partes.

Consciência e realidade nacional é o ponto de partida de um roteiro de considerações que reaparecerá e será complementado nos livros El pensamiento crítico en demografía e Ciência e existência, culminando no amplo painel tecido em $O$ conceito de tecnologia. Esse roteiro, mesmo que de forma indireta, quer demonstrar as possibilidades do homem considerado (apressadamente) inculto.

A incultura, no seu entender, não corresponde a ausência de conhecimento, mas sim a um grau da própria cultura de um tempo. Um exemplo dos efeitos desse modo de pensar (o qual, inclusive, foi bastante utilizado por Paulo Freire) pode ser obtido na sua definição de analfabetismo. Segundo Vieira Pinto, e novamente à mercê de Hegel, o analfabetismo não é uma essência em si, mas sim um grau do próprio alfabetismo. Ou seja, se existem pessoas plenamente alfabetizadas, existem também aquelas que estão "alfabetizadas em escala zero". Se a letra e a gramática são também bens tecnológicos, o manuseio dessa "tecnologia" conduz a um lugar na gradação do alfabetismo. Como em tudo na vida, o não-manuseio ou o manuseio de ferramentas precárias tem como contrapartida um subdesenvolvimento intelectual responsável pelo "lugar de cada qual" numa escala em que coexistem graus diferentes de avanço e apropriação tecnológica. ${ }^{5}$

O trabalho e a forma de trabalhar estão na base daquilo que os alemães chamariam de Weltanschauung,

${ }^{5}$ Essa é também outra demonstração de apreço e atenção às idéias cepalinas. Admite-se a existência "de tempos simultâneos, mas não coetâneos", aliás, expressão utilizada também no âmbito UNESCO de financiamento de pesquisas relacionadas às questões raciais. 
fato este que encontra guarida também na obra de Vieira Pinto: "o modo pelo qual o homem vê o mundo tem como uma das causas condicionadoras a natureza do trabalho que executa e a qualidade dos instrumentos e processos que emprega" (1960, p. 110, v. 1).

Mas há um dado fundamental que não pode deixar de ser mencionado e que constitui marca distintiva da personagem que está sendo aqui analisada: quando Vieira Pinto escrevia "trabalho", na maioria das vezes estava referindo-se a quem trabalha. Ou seja, estamos diante do filósofo que apostou suas fichas numa transformação radical da sociedade levada a efeito pelas mãos daqueles que operavam o mundo, especialmente os jovens entrando nos condomínios do trabalho.

Mas, nesse caso, como entender sua atenção ao mundo do trabalho, sua aposta política nas mãos dos que operam o mundo, se, enquanto analista social, se manteve à distância do conceito de classe social? Trata-se de uma pergunta sem resposta nos textos de Vieira Pinto. O conceito de classes sociais, quando se tornou mais palpável em sua obra, o que veremos mais adiante, não emergiu com força suficiente para derrubar um de seus principais pressupostos: o que de que existem contradições principais e contradições secundárias.

As contradições entre classes sociais, secundárias no seu entender, deveriam ser enfrentadas no sucedâneo do enfrentamento da contradição principal. Esta resultava do aviltamento que o capital estrangeiro operava sobre as nações subdesenvolvidas. Esse aviltamento, inclusive, era o responsável pela falta de acumulação de trabalho tecnicamente mais elaborado, de modo que favorecesse uma concentração de arcaísmos conveniente à manutenção da miséria social.

O filósofo convenceu-se de que o desenvolvimento acarretaria e facilitaria a emergência da consciência crítica que se espraiaria com o processo. Porém, considerava que esse seria um processo tanto lento quanto doloroso enquanto as estruturas arcaicas se mantivessem direcionando as decisões macroeconômicas do país. Vaticinava que as estruturas mantenedoras do atraso e da miséria não desapareceriam en- quanto fossem as responsáveis pelo dinamismo da economia. Com isso, indicava que relações econômicas e possibilidades tecnológicas mais elaboradas somente se instalariam no momento em que a luta política fosse capaz de evidenciar o esgotamento do modelo político de sociedade então presente. ${ }^{6}$

É quando o autor pensa em relações de produção mais elevadas que expressa com maior coerência o nexo entre seu corpus conceitual e sua aspiração política ao protagonismo dos trabalhadores. Se relações de produção mais elevadas não brotam espontaneamente, no seu entender elas medram, então, em conseqüência da experiência acumulada somente no mundo do trabalho. Todo trabalhador, ao participar da organização do futuro, estaria trazendo ao processo sua grande intimidade com a realidade.

O problema maior a ser enfrentado, no âmbito das lutas pelo desenvolvimento, apresentava-se como conseqüência da co-habitação da consciência crítica com a consciência ingênua. Essa co-habitação era descrita com a "metáfora do pêndulo". A realidade brasileira, no entender de Vieira Pinto, comportava-se como um pêndulo que toca ora as "zonas de aceleração da sociedade", ora as "zonas de retenção". Aceleração era o mesmo que industrialização e qualificação do trabalho das massas; retenção era o arcaísmo resultante do conluio entre as elites e o capital estrangeiro.

Para Vieira Pinto, quanto mais a consciência crítica conseguisse se estabelecer, ou seja, quanto mais o trabalhador recebesse condições mais elaboradas para

${ }^{6}$ Aqui é possível notar a assimilação que fazia de alguns momentos chave da obra de Marx. Por exemplo, vale frisar o seguinte paralelo: "Uma formação social não desaparece antes que se tenham desenvolvido todas as forças produtivas para as quais esta formação é suficiente e que novas e mais altas relações de produção tenham tomado seu lugar; antes que as condições materiais de existência destas últimas não tenham se formado no seio da própria sociedade [...]. Observando com mais cuidado, sempre se verifica que o próprio problema só surge onde já existem as condições materiais para sua solução ou onde estas condições já estão em processo de desenvolvimento" (Marx, 1969, p. 5-6). 
se apropriar do trabalho que já realizava, mais o pêndulo permaneceria retido nas zonas de aceleração, demorando a voltar aos condomínios do atraso, conseqüentemente, desmobilizando-o: “à medida que maior número de indivíduos ingressassem nas formas adiantadas de produção, ampliando, portanto, sua área de contato com a objetividade e aumentando seu interesse na transformação das coisas, o pensamento crítico passaria a preponderar" (Vieira Pinto, 1960, v. 2, p. 19).

Ao enunciar suas conclusões, o autor sentiu-se obrigado a estabelecer um estatuto epistemológico para o processo de aquisição da consciência obtido na assimilação de técnicas mais elaboradas de trabalho. Sua metodologia de análise em muito se assemelhava a uma "teoria da história". Não casualmente a denominava "empírio-historicismo", com o objetivo de comprovar que a história dos homens é, no fundo, a história do trabalho que fazem, e que cultura é a "forma como fazem". Buscava, por exemplo, o "parentesco" entre a pedra lascada e a caldeira na siderúrgica.

Quando se tornou um estudioso do trabalho, da disseminação da técnica e da tecnologia, deparou-se com um "desnivelamento universal" das fases de desenvolvimento e encontrou na ação do trabalhador um estratagema para cobrir "diferenças de etapa". A industrialização, por exemplo, teria o condão de "acelerar o tempo". Se existia para a humanidade um processo civilizatório capaz de englobá-la integralmente, o trabalho e a unificação do tempo teriam essências complementares. O papel da consciência, então, seria o de acelerar e desacelerar o tempo, conforme fosse crítica ou ingênua (Freitas, 1998, p. 108).

O trabalho artesanal que fazia com os conceitos foi bruscamente interrompido com os acontecimentos de março/abril de 1964. O autor, porém, prosseguiu investigando o conceito de trabalho, ainda que à mercê de uma situação bastante desfavorável para o trabalho sistemático de um filósofo.

\section{A reflexão na diáspora}

Os escritos seguintes de Vieira Pinto, que se mantiveram ao redor das categorias trabalho e tecno- logia, sofreram o impacto do dramático contexto no qual foram escritos. São textos da experiência de exílio que o intelectual viveu inicialmente na Iugoslávia, a partir de setembro de 1964, e que continuou no Chile, entre 1965 e 1968.

El pensamiento crítico en demografía e Ciência e existência foram escritos graças à intervenção de Paulo Freire, que conseguiu empregá-lo em Santiago como pesquisador do Centro Latinoamericano Caribeño de Demografía (CELADE). Pode parecer um despropósito ou apenas uma demanda típica de uma situação de emergência acomodar um filósofo da estatura de Vieira Pinto num centro dedicado a estudos demográficos. O resultado de seu trabalho, todavia, comprova o acerto contido na indicação de Freire.

O CELADE buscava acrescentar às investigações de natureza demográfica recursos analíticos com os quais as populações deixassem de ser consideradas apenas expressões numéricas que se comprovam com séries estatísticas.

Aquilo que Vieira Pinto chamou de conhecimento crítico em demografia na realidade resultava da soma de seus estudos nas áreas de antropologia e economia, os quais, reunidos ao seu vasto acervo de leituras filosóficas, favoreciam a ele apresentar uma produção original num campo costumeiramente habitado por números e gráficos.

Trata-se de um momento singular em sua trajetória intelectual, que nos permite apreciar a forma através da qual Vieira Pinto completou seus estudos sobre Marx. Ao mesmo tempo, é possível constatar que o autor conduzia a inserção do conceito de tecnologia em seus escritos, indicando, porém, tratar-se de um objeto que estava a reclamar uma sistematização sua, própria, longamente argumentada como produto de sua lavra.

Algo entre a síntese e o ecletismo, as operações de análise empreendidas pelo ex-professor do ISEB somavam sua recepção crítica da filosofia européia com algumas categorias marxianas. Um exemplo disso pode ser indicado na utilização da categoria "homemem-situação", cujo alcance ainda convencia plenamente o autor à medida que, segundo seu entendi- 
mento, as ferramentas analíticas de Marx não infirmavam o poder de síntese desse legado existencialista (Vieira Pinto, 1973, p. 44, p. 86 e ss.).

O "homem-em-situação" é o sujeito social morfologicamente confundido com o trabalho que exerce. Contudo, a mescla entre homem e trabalho não interrompe o contínuo processo de dominação da natureza por parte do trabalhador, mesmo porque nesse processo está contida a reelaboração constante da própria humanidade desse homem (idem, p. 203).

Quando o trabalho constitui o homem, a realidade constitui a sua situação. Nesta última estão presentes as suas reais possibilidades de comunicação (idem, p. 86). O trabalho, no seu entender, torna-se a chave de desvendamento da situação concreta, uma vez que, por ele e com ele, o sujeito adquire condições de perceber os limites do sistema social ${ }^{7}$ em que está inserido, e também com qual classe social poderia identificar-se, conceito este que passa a figurar no seu léxico, absorvido, porém, de maneira peculiar. ${ }^{8}$

Com isso, afrontava alguns cânones da demografia e afirmava que o trabalho não poderia ser considerado um dado interno de cada população. Propunha, ao contrário, que cada população fosse considerada dado interno a uma determinada possibilidade de trabalhar (Vieira Pinto, 1973, p. 244).

Isso tudo ajuda a entender porque, mesmo com tanto acúmulo e variação de leitura, o conceito de amanualidade não era posto de lado; ao contrário, sempre que possível o autor renovava sua crença no poder descritivo dessa categoria de análise.

${ }^{7}$ A noção de sistema social, reiteradas vezes utilizada em sua obra, corrobora a tese de que Vieira Pinto produzia também uma antropologia social baseada na análise da apropriação das ferramentas de trabalho.

${ }^{8} \mathrm{Na}$ circunstância em que se encontrava, Vieira Pinto proclamava estar à vontade para "misturar" o repertório de Heidegger e Husserl com o de Marx, afirmando ser isso uma decorrência e uma necessidade de quem "fala de outro lugar" que não a Europa. Esse outro lugar é o mundo subdesenvolvido (Vieira Pinto, 1973, p. 169-170).
Em sua argumentação, ainda permanecia válido aquilo que dissera em 1960: se o existencialismo europeu representava a consciência ingênua daqueles que "não precisam" mudar o mundo, a idéia de amanualidade, ao ser apropriada no mundo subdesenvolvido, tornava-se uma arma da consciência crítica que precisava e queria transformar a realidade (Vieira Pinto, 1960 , p. 67 , v. 1).

Tudo isso contribuía para que sua abordagem no campo da demografia se revestisse de originalidade e de alguma iconoclastia. Propunha, por exemplo, a minimização do uso das medidas, instrumentos de aferição e das quantificações, e sugeria, no lugar, o estudo intenso da qualidade de vida das populações pobres (Vieira Pinto, 1973, p. 14).

Se o mundo se apresentava cindido em realidades temporais diferentes, possibilitando o convívio de níveis de consciência distintos e, além disso, se modos de trabalhar qualitativamente opostos (desenvolvimento com subdesenvolvimento) compartilhavam do mesmo calendário, não havia situação que pudesse impedir o homem de "estar em comunicação" (idem, p. 86).

Como conseqüência dessa lógica interpretativa, construía uma missão para a demografia cumprir enquanto "ciência social", que consistia em captar a autoimagem que cada comunidade forjava de si mesma (idem, p. 97).

Essa missão se fazia acompanhar de uma proposta de renúncia. Propunha ao demógrafo do país subdesenvolvido renunciar aos conceitos "inaplicáveis ao terceiro mundo", tais como o de População Economicamente Ativa (PEA).

Esse rompimento epistemológico deveria ser celebrado como consequiência daquele "estar em comunicação", ou seja, cumpria ao investigador ouvir e apreender o significado exato do acesso ao incremento tecnológico no bojo de cada população. Isso porque, falando em termos semelhantes a Celso Furtado, escutar a opinião de quem trabalha deveria ser considerado um instrumento fundamental para impedir a absorção de tecnologias "poupadoras de mão-de-obra".

Aqui nos deparamos com um argumento que permite expurgar qualquer tentativa de fazer de Álvaro 
Vieira Pinto o defensor ingênuo das virtualidades da máquina e da tecnologia. É necessário frisar que sua atenção à tecnologia deriva de sua certeza de que passar do subdesenvolvimento ao desenvolvimento exige manusear o mundo de forma mais elaborada. $\mathrm{O}$ autor não deixava de perceber que se a chegada da máquina inviabilizasse a transformação qualitativa da "forma de manuseio" (do "grau de amanualidade") em relação à situação ao redor, o trabalhar passaria a poupar quem trabalha, roubando desse trabalhador o controle sobre sua própria qualificação. Sendo assim, até a proliferação da tecnologia poderia ser uma obra da consciência ingênua (idem, p. 69).

O que lhe importava defender é que o lidar diretamente com a técnica poderia ser um gesto de liberdade para a própria consciência do homem no país subdesenvolvido:

O trabalho que as massas executam funda sua visão de mundo. Nas formas inferiores, exploradas, humildes, o trabalhador não chega a ter senão uma noção sensível da realidade, e, ainda que deseje modificá-la, não alcança compreender como isso seria possível. Ao progredir nas formas de produção, se criam formas superiores de trabalho, realizado por um volume cada vez maior de pessoas, as quais, pela necessidade de fazê-lo bem, têm que possuir conhecimentos amplos. Precisam de instrução técnica e uma formação cultural que tende sempre a crescer, sem possibilidade de que interesses na execução do trabalho possam fixar-lhe um limite. A consciência do trabalhador, uma vez despertada, se descobre como um processo individual sempre mais independente. Com isso, sua percepção da realidade se engrandece, e aprofunda o conhecimento das causas de sua situação; e assim o indivíduo é levado a uma interpretação de si mesmo, de seu papel no mundo e na sociedade. (idem, p. 244-245)

Quando considerou que a consciência crítica vislumbrava a liberdade, Vieira Pinto deparou-se com um problema de natureza exegética. Andava às voltas com o conceito de ideologia (idem, p. 246-256), e não se esquivava da advertência de Marx sobre o fato de que o próprio homem se tornava bem de produção para quem dispunha de seu trabalho.
No bojo de sua argumentação, surgia a necessidade de definir com mais clareza se considerava o trabalho realmente uma possibilidade de libertação da consciência ou se a retificação marxiana, ao ser acolhida, deveria provocar uma inflexão em seus ensaios e, como conseqüência, conduzir o autor a relacionar trabalho com opressão.

Resolveu esse dilema recorrendo à noção de "fase histórica", amplamente discutida nos tempos de ISEB e que se mantinha bastante viva nas manifestações políticas e culturais dos movimentos assim chamados de "terceiro-mundistas". Propunha então, com todas as letras, uma "antropologia existencial para o Terceiro Mundo", e explicava que a co-existência de "populações simultâneas, mas historicamente não coetâneas" (idem, p. 284) facultava a algumas compreender o trabalho como instrumento de passagem da consciência ingênua para a consciência crítica, e a outras compreender o trabalho como expressão da opressão de classe contra classe. Seu argumento, enfim, acomoda as duplicidades que levanta quando trata das questões relacionadas ao trabalho:

Quem vive ao nível da economia de simples subsistência tem preocupações tão elementares e imediatas que a consciência está ocupada totalmente pelo penoso afã de produzir a vida [...]. Não existem leis gerais sobre a população, válidas para toda a humanidade em todas as épocas e lugares, simplesmente porque cada fase histórica se define por condições superestruturais políticas que lhes são particulares e condicionam a correlativa configuração do processo demográfico, distinguindo-o das caracterizações que assume em outras épocas... [Na periferia do capitalismo] as nações são um conglomerado de estamentos sociais representativos de fases históricas distintas, coexistindo no mesmo espaço geográfico. (idem, p. 280-283)

No bojo dessas considerações, Vieira Pinto indicou que sua acepção de tecnologia encarecia uma demonstração detida e aprofundada das possibilidades contidas no conceito. Explicar a técnica como "memória social do fazer novo" demandava um esforço filológico capaz de orientar seus leitores sobre a importância de um "projeto nacional" capaz de direcionar 
as políticas de educação popular para "longe dos problemas meramente pedagógicos" e para dentro das demandas de cada fase, antecipando, como consciência social, o convívio com as alterações materiais responsáveis pelo trânsito de uma fase à outra (Vieira Pinto, 1960, p. 89, v. 1).

Governar, no seu entender, supondo sempre um governo popular, equivalia também a expandir ciência e acumular trabalho industrial na sociedade. Sua concepção de governo-ciência rejeitava o que chamava de pedagogia ingênua, segundo a qual incentivar a ciência correspondia a evoluir o país e, a reboque, educar seu povo. Não considerava o povo desprovido de ciência, nem de escolaridade. Considerava-o, sim, mergulhado em condições precárias de trabalho, o que não facultava aos governos apresentar ciência e cultura como se fossem novidades ao trabalhador (Freitas, 1998, p. 185).

Essa reflexão de Vieira Pinto foi acompanhada de um esforço considerável de organização de uma plataforma metodológica a partir da qual outras investigações sobre o papel da ciência, da tecnologia e do trabalho na organização da sociedade pudessem continuar o caminho por ele iniciado.

Nesse sentido, o livro Ciência e existência, para além da metodologia do trabalho científico, apontou campos de debate que deveriam ser percorridos para que a ciência no Brasil pudesse amadurecer e contribuir para com a emancipação do país. Vale notar que, na organização dos argumentos escolhidos para compor sua análise a respeito das tensões sociais existentes entre ciência e existência, o autor viu-se obrigado a refutar qualquer aproximação entre suas idéias e aquelas relacionadas ao uso dos conceitos conhecimento científico e de experiência no âmbito do pragmatismo, especialmente aquele difundido nos Estados Unidos por John Dewey (Vieira Pinto, 1979, p. 446).

Vieira Pinto considerava que os pragmatismos defendidos até então tomavam a realidade como ponto de chegada, enquanto seu trabalho se esforçava por demonstrar que a realidade é um ponto de partida para a compreensão dos processos de aquisição de conhecimento por parte do homem que trabalha (idem, p. 341).
É nesse particular que o livro Ciência e existência lança as bases de futuros escritos com os quais seu relacionamento com Paulo Freire ficaria mais evidente. É no intento de distanciar-se do pragmatismo norte-americano que o autor dá início a uma certa "didatização" do seu programa de ciência, com o que, em pouco tempo, se viu envolvido com programas de alfabetização propriamente ditos.

De Ciência e existência retirou pressupostos que reapareceriam com outra elaboração noutros estudos, como por exemplo:

O primeiro passo para a constituição da autoconsciência crítica do trabalhador, da qual decorre necessariamente a aquisição da linguagem escrita, está em fazê-lo tornar-se observador consciente de sua realidade; destacar-se dela para refletir sobre ela, deixando de ser apenas participante inconsciente dela (e por isso incapaz de discuti-la). Tecnicamente, esse resultado é alcançado mediante a apresentação ao educando adulto de imagens de seu próprio meio de vida, de seus costumes, suas crenças, práticas sociais, atitudes de seu grupo etc. Com isso, o alfabetizando se torna espectador e pode discutir sua realidade, o que significa abrir o caminho para o começo da reflexão crítica, do surgimento de sua autoconsciência. A alfabetização decorre como conseqüência imediata da visão da realidade, associando-se a imagem da palavra à imagem de uma situação concreta. Posteriormente, a decomposição da palavra em seus elementos fonéticos e a recomposição destes em outras palavras se faz sem nenhuma dificuldade e é um produto da criação intelectual do próprio educando (e não uma sugestão externa que lhe é imposta pelo professor). (Vieira Pinto, 1991, p. 99)

A reflexão de Vieira Pinto sobre o relacionamento do homem com a realidade, observando a mediação do trabalho no processo de "transição da consciência ingênua para a consciência crítica", chegou a tal ponto de detalhamento que, ao termo, o conjunto vasto de seus escritos demonstrou que mesmo as imprevisibilidades contidas nas conjunturas desfavoráveis pelas quais passou não conseguiram distanciálo de seu projeto intelectual primeiro. Sua proposta 
de fazer um périplo ao redor do "continente trabalho" manifestou-se em todos os seus escritos.

O movimento circular que empreendeu se completou no livro $O$ conceito de tecnologia, de certa forma um livro onipresente em toda a sua obra.

\section{O laboratório e a capelinha}

A obra de Álvaro Vieira Pinto poderia ser estudada à luz do conceito de "biografia total" sugerido por Le Goff (1999). Ou seja, poder-se-iam articular três perspectivas antes de enfrentar seu campo conceptual. Na primeira elucidaríamos a relação entre biografia e tempo vivido; na segunda passaríamos "por dentro" da memória construída sobre o autor e seus escritos; por fim, na terceira perspectiva abriríamos sua caixa de conceitos como quem abre uma caixa de ferramentas.

Estupefatos ante sua caixa de ferramentas, provavelmente compreenderíamos o porquê de tantas páginas. Para empreender o movimento analítico que Vieira Pinto realizou, chamando ao seu trabalho tantos interlocutores, são, de fato, necessárias as milhares de páginas que escreveu em ritmo monástico.

Um mérito de um de seus últimos escritos - $O$ conceito de tecnologia - é o de revelar que os textos do "ciclo desenvolvimentista" não foram apenas panfletos de uma hora que se apresentava como prenúncio da "revolução brasileira".

Se os panfletos apareceram, especialmente quando Vieira atuou em conjunto com alguns intelectuais que se movimentaram do "ISEB para os comícios" (Freitas, 1998, p.113), os livros propriamente ditos do autor ${ }^{9}$ não devem ser simplesmente destacados como se fossem uma parte de um suposto populismo inerente ao "interesse pelas massas".

É verdade que muitos escritos foram concebidos como instrumentos de mobilização, denúncia e convocação da juventude ao engajamento. Mas o círculo

${ }^{9}$ Ver especialmente Por que os ricos não fazem greve? (1962) e A questão da universidade (1986). interpretativo fechado com o livro transcende qualquer demanda da voz das ruas. É um tratado filosófico de amplo alcance.

$O$ conceito de tecnologia parece ser, ao mesmo tempo, o ato conclusivo de Consciência e realidade nacional, tendo El pensamiento crítico en demografía e Ciência e existência como "entreatos" e também a forma escrita com a qual o intelectual interveio no sentido de oferecer uma fisionomia para o tempo que testemunhava, como diria Walter Benjamim. É um texto singular. Nele o autor solucionou impasses teóricos e definiu com qual espectro de autores contou para fazer do conceito de amanualidade uma recriação sua, roubando-o definitivamente do existencialismo europeu.

O retorno empreendido neste livro às origens das palavras técnica e tecnologia, acompanhado da análise das sucessivas reapropriações dos conceitos, análise esta sempre feita "por dentro" e com familiaridade com inúmeros clássicos da filosofia, não deve sugerir a produção de um manual da história do uso de um conceito. Embora esbanje conhecimento, a intenção do autor não é filológica, mas é sim, como fazem as tecelãs, um gesto de organização dos fios com os quais o desenho teórico de sua vida ganhou feição definitiva.

Vieira Pinto recusa a expressão "era tecnológica", que começa a ganhar forma naquele momento, lançando mão de um argumento direto e contundente: $\mathrm{o}$ homem não seria humano se não vivesse sempre numa era tecnológica.

Com esse ponto de partida, já podemos antever a raiz política de $O$ conceito de tecnologia: qualquer "desnível" entre os povos resulta da apropriação indébita que as nações ricas fazem das riquezas do mundo subdesenvolvido. A existência de tempos contemporâneos, mas não coetâneos, era, antes de tudo, diferença de acesso aos avanços tecnológicos, e por isso Vieira Pinto gastou muitas páginas demonstrando seu desconforto para com os argumentos de origem biológica e racial.

O "desnível” entre sociedades é explicado com argumentos que tentam desmistificar a presença da tec- 
nologia na sociedade, preferindo, ao contrário, indicar que, quanto mais vulgarizado estiver seu uso, mais o homem estaria agindo a favor do controle racional dos bens da natureza. Eis sua definição de processo:

À medida, porém, que vão sendo compreendidos os processos naturais e descobertas as forças que os movimentam, com a conseqüente possibilidade de utilização delas pelo homem, para produzir artefatos capazes de satisfazer novas necessidades, e essa fabricação se multiplica constantemente, o mundo deixa de ser o ambiente rústico espontâneo e se converte em ambiente urbano, na casa povoada de produtos de arte e, na época atual, de aparelhos que põem as forças naturais a serviço do homem. (Vieira Pinto, 2005, p. 47, v. 1)

No momento em que o autor demonstra que uma situação de superação em relação ao "rústico espontâneo" acompanha inexoravelmente a utilização dos bens tecnológicos, o texto que agora aparece conclui a exposição de um argumento que perpassa toda a sua obra: convém ao pobre usar a tecnologia tanto quanto convém ao rico. Não se sustenta a análise apresentada por alguns de seus críticos mais eruditos de que Vieira Pinto poderia ser considerado "expressão da razão burguesa" ou "exemplo de retórica messiânica" direcionada ao homem rústico (Franco, 1985; Paiva, 1986).

Recentemente, Cortes (2003) demonstrou que, na acepção esperançosa de Vieira Pinto, a democracia é o regime que interessa aos "homens comuns". Essa afirmação pode ser complementada com a leitura de um dos aforismos expressos em $O$ conceito de tecnologia: a idéia de "era tecnológica" é uma operação ideológica com a qual cada grupo dominante apresenta sua versão de "fim da história". O momento no qual se triunfa passa a ser o momento no qual a história estaria vivendo seu ápice. ${ }^{10}$

${ }^{10}$ Diz Vieira Pinto: "O conceito de era tecnológica encobre, ao lado de um sentido razoável e sério, outro, tipicamente ideológico, graças ao qual os interessados procuram embriagar a consciência das massas, fazendo-as crer que têm a felicidade de viver
O que Vieira Pinto enxerga no contexto em que analisa a propagação das imagens da "era tecnológica" é, ao contrário, um mergulho no provincianismo próprio da consciência ingênua: "o laboratório de pesquisas, anexo à gigantesca fábrica, tem o mesmo significado ético da capelinha outrora obrigatoriamente exigida ao lado dos nossos engenhos rurais" (Vieira Pinto, 2005, p. 170, v. 1).

As consequiências que o autor retira do esforço de debulhar o conceito de tecnologia têm alcance expressivo e tocam aspectos dramáticos dos dias que seguem. Vieira Pinto demonstra que um dos maiores danos causados pelo desnível entre países desenvolvidos e subdesenvolvidos é a disseminação da crença de que grandes problemas resultam somente da ineficiência de gestão e falta de instrumentos adequados de "engenharias sociais". Ele sobe o tom e posicionase: "contra esta errônea e insidiosa uniformização é que nos pronunciamos". (idem, p. 41)

E, como em toda a sua obra, diante da necessidade de recusar imposturas ideológicas, na seqüência o autor abre espaço à antropologia para complementar sua argumentação:

Uma das mais nocivas substancializações que cometemos quase inconscientemente, passando assim despercebida, é a que se refere à cultura. Aparece-nos como uma realidade em si. Definimos então as técnicas declarando-as pertencentes a certa cultura, substantivada, entificada, quando a verdade encontra-se na expressão inversa. [...] Atribuímos certas técnicas antiquíssimas por exemplo à cultura paleolítica, quando deveríamos dizer o oposto, pois são as técnicas executadas em tal fase do desenvolvimento humano que configuram o conceito chamado cultura paleolítica. (Vieira Pinto, 2005, p. 106, v. 2)

nos melhores tempos jamais desfrutados pela humanidade. [...] [Por isso ocorre] a conversão da obra técnica em valor moral. [Como se] a sociedade capaz de criar as estupendas máquinas e aparelhos atualmente existentes, desconhecidos e jamais sonhados pelos homens de outrora, não pode deixar de ser melhor do que qualquer outra precedente." (idem, p. 61) 
Olhando mais uma vez para os desníveis entre as sociedades, Vieira Pinto acredita que alguém agressivamente chamado "primitivo", vivendo praticamente ocupado todo o tempo nos afazeres da subsistência individual e da espécie, está muito mais imerso numa sociedade tecnocrática do que nós, que dispomos de maior liberdade de movimentos.

Vieira Pinto prefere dizer que quanto mais se desenvolve a tecnologia tanto mais regride a tecnocracia. Por isso, recusou-se a ver na disseminação do uso da máquina e do computador um elemento comprovador da "qualidade" presente na opção vulgarmente defendida pelas elites de então: entrar na era tecnológica para superar a desigualdade.

Seu raciocínio, nesse sentido, é lapidar e radicalmente ao avesso: sem acabar com a desigualdade, não deixaria de ter importância a ferramenta rústica na sociedade.

\section{Considerações finais}

Diante do exposto, qual a tese de Vieira Pinto no que toca aos benefícios que a máquina traz à sociedade? Sua resposta é enxuta: "a verdadeira finalidade da produção humana consiste na produção das relações sociais, a construção das formas de convivência" (2005, p. 169, v. 2).

Com isso o autor retorna, como o faz, aliás, em toda a sua obra, ao conceito de amanualidade, para afirmar que o homem cria o engenho para que este produza melhor os bens, que, por sua vez, irão recriar o mesmo homem, no sentido de lhe darem condições mais convenientes de existência. Na forma como Vieira Pinto se apropriou e recriou o conceito de amanualidade, há um dado que merece nossa atenção e que diz respeito à entrada em cena de uma acepção de história para pensar socialmente a tecnologia: "as estupendas criações cibernéticas com que hoje nos maravilhamos resultam apenas do aproveitamento da acumulação social do conhecimento, que permitiu fossem concebidas e realizadas. Não derivam das máquinas anteriores enquanto tais, mas do emprego que o homem fez delas" (2005, p. 9, v. 2).
Seu destaque para o caráter social do incremento tecnológico reaparece em muitas partes de vários textos que escreveu. No caso do livro $O$ conceito de tecnologia, a evocação do social foi necessária para pontuar sua rejeição ao argumento de que a disseminação da técnica mais elaborada dependerá da generosidade de quem a usa em benefício próprio. A tecnologia já pertence aos estratos mais simples da sociedade. Esses estratos não podem ganhar, na condição de dádiva, aquilo que já é constitutivo do seu próprio ser social.

Vieira Pinto, ao longo de todo o texto, tenta chamar a atenção para um elemento que, a seu ver, deveria ser o organizador das iniciativas voltadas para a construção do desenvolvimento econômico. Trata-se da percepção, que carrega desde o final da década de 1950, quando começou a redigir Consciência e realidade nacional, de que o homem só trabalha para si quando o faz para a sociedade inteira. ${ }^{11}$

O livro $O$ conceito de tecnologia é aquele no qual Vieira Pinto mais concede espaço a Marx para refletir sobre a categoria trabalho, estendendo essa abertura a alguns debates especificamente levados a efeito por Engels.

Isso provoca um certo deslocamento no seu modo de entender os efeitos da tecnologia sobre a sociedade. Na realidade, não ocorre exatamente um deslocamento, mas sim uma operação de confirmação de seus pressupostos políticos, sem prejuízo de sua malha conceptual.

À medida que Vieira Pinto vai acolhendo em suas próprias páginas, e não só vai acolhendo, como vai demonstrando familiaridade com os cânones da economia política marxiana, torna-se definitiva a necessidade de posicionar-se a respeito da questão de fundo: o trabalho aliena ou não o homem? Se parte expressiva de sua obra se dedicou a defender a necessidade de elevar o padrão de qualidade na interven-

\footnotetext{
${ }^{11}$ Ele diz, de forma quase singela: "O avião não foi feito
} para voar, mas para o homem voar". (Vieira Pinto, 2005, p. 80, v. 1) 
ção do homem sobre a natureza, o desafio exposto na teoria da mais-valia sugeriu ao autor uma saída "por dentro" de seus próprios labirintos. Ou seja, primeiro dedicou-se a refutar qualquer aproximação entre sua análise sobre o valor da técnica e os argumentos irracionalistas que povoaram o século XX. Da obra de Oswald Splengler, por exemplo, não sobra pedra sobre pedra em suas análises.

Mas esse processo de revigoração dos próprios pressupostos, sem procurar estabelecer incompatibilidades com o marxismo, foi operacionalizado no plano da política, ou seja, concluiu que o trabalho aliena quando não pertence mais ao trabalhador.

Por isso, para surpresa do leitor de sua obra, Vieira Pinto decide explicitar, como nunca fizera antes, que o trabalho deveria ser "desalienado" pelas mãos do jovem trabalhador no ato da apropriação da técnica mais elaborada "a seu favor". Com isso, declara sua distância em relação a outras compreensões do conceito de amanualidade, indicando que a liberdade do mundo do trabalho não resultaria da recusa em participar do mundo tecnológico, buscando na simplicidade e no simples "em si" uma forma mais elaborada de vida.

O livro $O$ conceito de tecnologia proporciona ao leitor testemunhar um denso diálogo com a filosofia existencialista de Martin Heidegger. O ponto de partida é simples: se a tecnologia representava a vitória do homem sobre a natureza, não lhe parecia plausível defender o "retorno para ela" como forma de colocar o homem no centro da história.

Sua interpelação é contundente:

Lamentar o avassalamento da existência pela tecnologia, o perigo a que estão expostos, ou mesmo a que já sucumbiram os valores humanos, não passa de pura fraseologia de escritores impressionistas, alguns com banca montada e renome de filósofos profissionais. É o caso, por exemplo, de Martin Heidegger, que declara: a técnica é um malefício de que o homem deve fugir para se abrigar na inexpugnável força do simples. (Vieira Pinto, 2005, p. 719, v. 2)

Com essa reprimenda a Heidegger, Vieira Pinto outorgou a si a condição de novo formulador de um existencialismo pronunciado da periferia para o centro. Pensou nas condições objetivas de vida e trabalho do povo brasileiro, e atribuiu à juventude um protagonismo essencial na procura pelo avesso do mundo subdesenvolvido. Pensava que os jovens poderiam renovar a idéia de "projeto nacional". Pensava, fundamentalmente, que as condições de arcaísmo e rusticidade na qual boa parte do povo brasileiro se encontrava não deveriam ser interpretadas como sintomas de um "povo atrasado", mas sim como se fossem as bases de reconstrução de uma nacionalidade.

Reconstrução nacional, no seu entender, demandava um esforço considerável no sentido de oferecer para toda a juventude condições de manuseio de tecnologia cada vez mais elaborada. Essa tecnologia seria tanto mais elaborada quanto mais fosse socialmente disseminada, ou seja, quanto menos estivesse vinculada aos mecanismos de acumulação individual de riqueza.

\section{Referências bibliográficas}

BIELSCHOWSKY, Ricardo. Pensamento econômico brasileiro: o ciclo ideológico do desenvolvimentismo. Rio de Janeiro: Contraponto, 1995.

CORTES, Norma. Esperança e democracia. Belo Horizonte: Editora da UFMG, 2003.

FRANCO, Maria Sylvia Carvalho. O tempo das ilusões. In: FRANCO, Maia Sylvia Carvalho; CHAUÍ, Marilena. Ideologia e mobilização popular. Rio de Janeiro: Paz e Terra / CEDEC, 1985. p. 151-209.

FREITAS, Marcos Cezar de. Álvaro Vieira Pinto: a personagem histórica e sua trama. São Paulo: Cortez, 1998.

FURTADO, Celso. Desenvolvimento e subdesenvolvimento. Rio de Janeiro: Fundo de Cultura, 1961. . Dialética do desenvolvimento. Rio de Janeiro: Fundo de Cultura, 1964.

. A fantasia organizada. Rio de Janeiro: Editora Paz e

Terra, 1985 . 
. Formação econômica do Brasil. São Paulo: Editora

Nacional, 1971.

. A pré-revolução brasileira. Rio de Janeiro: Fundo

de Cultura, 1962.

Projeto para o Brasil. Rio de Janeiro: Saga, 1968.

LE GOFF, Jacques. São Luís. Rio de Janeiro: Editora Record, 1999.

MARX, Karl. Perla critica dell'economia politica. Roma: Riuniti, 1969.

PAIVA, Vanilda Pereira. Paulo Freire e o nacionalismo desenvolvimentista. Rio de Janeiro: Civilização Brasileira, 1986.

PREBISCH, Raul. Estudio económico de América Latina. Nova York: CEPAL/Nações Unidas, 1951.

.The economic development of Latin America and its principal problems. Nova York: ONU, 1950.

RODRIGO, Lidia Maria. O nacionalismo no pensamento filosófico. Petrópolis: Vozes, 1988.

ROUX, Jorge. Álvaro Vieira Pinto: nacionalismo e terceiro mundo. São Paulo: Cortez, 1990

TOLEDO, Caio Navarro de. ISEB: fábrica de ideologias. São Paulo: Ática, 1982.

Teoria e ideologia na perspectiva do ISEB. In:

MORAES, Reginaldo et al. (Orgs.). Inteligência brasileira. São Paulo: Brasiliense, 1986. p. 224-256.

VIEIRA PINTO, Álvaro. Ciência e existência. Rio de Janeiro: Paz e Terra, 1979.

. O conceito de tecnologia. Rio de Janeiro: Contraponto, 2005. $2 \mathrm{v}$.

Consciência e realidade nacional. Rio de Janeiro:

ISEB, 1960. $2 \mathrm{v}$.

Ideologia e desenvolvimento nacional. Rio de Janeiro: ISEB, 1956.
El pensamiento crítico en demografía. Santiago:

Centro Latinoamericano de Demografía (CELADE), 1973.

Por que os ricos não fazem greve? Rio de Janeiro:

Civilização Brasileira, 1962 (Cadernos do Povo Brasileiro, v. 4).

A Questão da universidade. São Paulo: Cortez /

Autores Associados, 1986.

Sete lições sobre a educação de adultos. São Paulo:

Cortez / Autores Associados, 1991.

MARCOS CEZAR DE FREITAS, doutor em história e filosofia da educação pela Pontifícia Universidade Católica de São Paulo (PUC-SP), com pós-doutorado em filosofia da educação pela Universidade de São Paulo (USP), é professor do Programa de Estudos Pós-Graduados em Educação: História, Política, Sociedade da PUC-SP e pesquisador da Faculdade Latino-Americana de Ciências Sociais (FLACSO), no Grupo de Investigación Pobreza y Desigualdad Social entre Niños y Jóvenes, e também do Conselho Nacional de Desenvolvimento Científico e Tecnológico (CNPq). Publicações recentes: Da micro-história à história das idéias (São Paulo: Cortez, 1999); História, antropologia e a pesquisa educacional (São Paulo: Cortez, 2001); Álvaro Vieira Pinto: a personagem histórica e sua trama (São Paulo: Cortez, 1998); Integralismo: fascismo caboclo (São Paulo: Ícone, 1998); Alunos rústicos, arcaicos e primitivos: o pensamento social e a educação (São Paulo: Cortez, 2005). Organizou História social da infância no Brasil (São Paulo: Cortez, 2001); Os intelectuais na história da infância (São Paulo: Cortez, 2002); Desigualdade social e diversidade cultural na infância e na juventude (São Paulo: Cortez, 2006).E-mail: mcezar@pucsp.br
Recebido em setembro de 2005

Aprovado em dezembro de 2005 
Palabras claves: prácticas de lectura y escritura; tecnologías de información y comunicación; computadoras; estudiantes de enseñanza media superior; aproximación sociocultural; investigación cualitativa

O deslocamento de práticas impressas e a apropriação de práticas digitais.

Um estudo com alunos do ensino médio tecnológico aprendendo a usar o computador na escola

São apresentados os resultados de um projeto de pesquisa qualitativa centrado nas práticas de leitura e escrita de oito pares de alunos de ensino médio, que usam o computador. Com uma abordagem sociocultural, este trabalho analisa eventos alfabetizadores gravados em áudio e vídeo. As descobertas revelam como os alunos desenvolvem diversas práticas de leitura e escrita dependendo do tipo de produção e conhecimento que se requer para sua realização. Também explica como suas práticas são transformadas em processos de mudança do ambiente impresso para culturas digitais. $O$ estudo conclui que as tecnologias da informação e comunicação abrem as portas para mundos com múltiplas formas de ler e escrever, numa relação complementar com o mundo impresso. Esta situação leva a considerar o papel da educação na formação de leitores/ escritores críticos, versáteis, criativos e competentes.

Palavras-chave: práticas de leitura e escrita; tecnologias de informação e comunicação; computadores; estudantes do ensino médio; contexto sociocultural; pesquisa qualitativa

The substitution of printed practices and the appropriation of digital practices: a study of students of the technological baccalaureate learning to use computers at school Presents a qualitative research on the literacy practices of eight dyads of high school students, whom use the computer to accomplish their school tasks. The article analyses literacy events recorded in audio and videotape from a sociocultural perspective. It reveals that the students develop different literacy practices according to the kind of production and knowledge of softwares needed to accomplished their school tasks. It concludes that the new technologies of communication provide access to worlds of multiple ways of reading and writing, based on those we already know, but that education should not omit its role in the formation of critical and competent readers and creative and versatile writers; after all, computers do not teach how to read and write electronically.

Key-words: literacy practices; ICT; computers; high school students; sociocultural approach; qualitative research

Marcos Cezar de Freitas

Economia e educação: a contribuição de Álvaro Vieira Pinto para o estudo histórico da tecnologia Este artigo analisa a contribuição de Álvaro Vieira Pinto para os estudos de economia e educação. Seu conceito de trabalho tecnologicamente elaborado pode ser reconhecido como resultado de uma profunda investigação sobre as relações humanas que encontramos na "cultura da economia". Seu caminho teórico até os escritos de Marx aponta uma capacidade erudita de relacionar educação e emancipação política com a história da tecnologia.

Palavras-chave: economia; educação; tecnologia; cultura

Economy and education: Álvaro Vieira Pinto's contribution to historical studies on technology This paper analyses Álvaro Vieira Pinto's contribution to studies on economy and education. His concept of technologically elaborated work should be understood as the result of profound research into human relations which we find in the "culture of economics". His theoretical encounter with Marx's writings reveals an erudite capacity to relate education and political emancipation with the history of technology.

Key-words: economy; education; technology; culture

Economía y educación: la contribución de Álvaro Vieira Pinto para el estudio histórico de la tecnología

Este artículo analiza la contribución de Álvaro Vieira Pinto para los estudios de economía y educación. Su concepto de trabajo tecnológicamente elaborado puede ser reconocido como resultado de una profunda investigación sobre las relaciones humanas que encontramos en la "cultura de la economía". Su camino teórico hasta los escritos de Marx, muestran una capacidad erudita de relacionar educación y emancipación política con la historia de la tecnología.

Palabras claves: economía; educación; tecnología; cultura

Ana Waleska P. C. Mendonça, Libânia Nacif Xavier, Vera Lucia Alves Breglia, Miriam Waidenfeld Chaves, Maria Teresa Cavalcanti de Oliveira, Cecília Neves Lima, Pablo S. M. Bispo dos Santos

Pragmatismo e desenvolvimentismo no pensamento educacional brasileiro dos anos de 1950/1960 $\mathrm{O}$ artigo analisa as formas de apropriação do ideário da Escola Nova no Brasil, particularmente do pragmatismo deweyano, nos anos de 1950/1960. Parte-se do pressuposto de que a ideologia desenvolvimentista que pontuou o debate em torno da reestruturação econômica, política e social do país nessas duas décadas constituiu-se em um solo fértil para a retomada e a expansão do ideário pragmatista entre os educadores brasileiros, articulando-se, de forma al- 